\title{
Emergence of neuronal diversity from patterning of telencephalic progenitors
}

Roberta Azzarelli \#, Laura J. A. Hardwick, Anna Philpott \#

Department of Oncology, University of Cambridge, Hutchison/ MRC Research Centre, Cambridge Biomedical Campus, Cambridge CB2 0XZ, UK.

\# To whom correspondence should be addressed.

E-mail: ra461@cam.ac.uk (R.A.), ap113@cam.ac.uk (A.P.)

Tel.: 44-1223-762675; Fax 44-1223-336902;

Key words: Telencephalon; Patterning; Cortical Development; Neuronal Specification; Ventral Forebrain. 


\section{ABSTRACT}

During central nervous system (CNS) development, hundreds of distinct neuronal subtypes are generated from a single layer of multipotent neuroepithelial progenitor cells. Within the rostral CNS, initial regionalization of the telencephalon marks the territories where the cerebral cortex and the basal ganglia originate. Subsequent refinement of the primary structures determines the formation of domains of differential gene expression, where distinct fate-restricted progenitors are located.

To understand how diversification of neural progenitors and neurons is achieved in the telencephalon, it is important to address early and late patterning events in this context. In particular, important questions include: How does the telencephalon becomes specified and regionalized along the major spatial axes? Within each region, are the differences in neuronal subtypes established at the progenitor level or at the postmitotic stage? If distinct progenitors exist that are committed to subtype-specific neuronal lineages, how does the diversification emerge? What is the contribution of positional and temporal cues and how is this information integrated into the intrinsic programs of cell identity? 


\section{INTRODUCTION}

One of the biggest challenges in developmental neurobiology is to understand how hundreds of distinct subtypes of neurons are generated from spatially and temporally related progenitor pools.

Regional patterning of the neural tube along antero-posterior (AP) and dorso-ventral (DV) axes represents one of the earliest events in the formation of distinct central nervous system (CNS) structures. This is achieved through the concerted activity of a series of organising centres that release diffusible signalling factors and ultimately give rise to progenitor cells with positional identity.

The molecular mechanisms of cell fate specification have been predominantly studied in the spinal cord, where progenitor cells integrate cues from morphogen gradients to establish progenitor domains that are defined by unique transcription factor codes ${ }^{1}$. Discrete subtypes of spinal motor and interneurons later arise from these different domains with exquisite spatial precision.

In comparison with the spinal cord, in the telencephalon, the scenario is complicated by the multitude of different neuronal types and by the complexity of their spatial organisation into tri-dimensional structures, as opposed to the simpler tubular arrangement of more posterior CNS regions.

Although progress has been made in understanding the formation of the primary telencephalic subdivisions, molecular mechanisms that underlie the diversification of initially multipotent progenitor cells remain unknown. Furthermore, the means by which individual progenitors can temporally generate a sequence of different cell types is still the subject of intensive research.

Here, we focus on the developing telencephalon and consider how intrinsic and extrinsic, spatial and temporal factors can interact to pattern neural progenitor cells, ultimately generating the immense neuronal diversity required for a functioning CNS.

\section{SPECIFICATION OF TELENCEPHALIC TERRITORY}

During the development of the mammalian central nervous system (CNS), the coordination of growth and patterning of the neural tube shapes the single-layered neuroepithelium into distinct yet connected brain structures. The brain arises from a series of vesicles at the cephalic end of the neural tube (Fig. 1A) with subsequent development, folding 
and differential enlargement giving rise to the subdivisions of the fore-, mid- and hind-brain regions ${ }^{2}$. The first stage in the specification of the telencephalic territory is the acquisition of anterior identity within the prosencephalic vesicle. A two-step model proposes that the neuroectoderm adopts an anterior identity during initial neuralisation, and in a subsequent step, the prospective caudal regions are posteriorised in response to a gradient of secreted factors such as members of the Wnt family. Prospective anterior forebrain regions are protected from this posteriorising effect through both the secretion of Wnt antagonists from the anterior patterning centres, and by reduced responsiveness of anterior progenitors to Wnt signalling 3,4. Two early anterior neural fate determinants, Hesx1 and Six3 repress the expression of Wnt signalling components such as Axin2 and Wnt1 respectively; the importance of this mechanism being emphasised in the Hesx1 and Six3 mutant embryos that fail to maintain anterior forebrain identity and instead exhibit rostral expansion of posterior markers ${ }^{5-10}$.

However, anterior identity is also under active control through Fgf signalling 5, 11. The anterior neural ridge at the most anterior neural border also secretes several Fgf ligands, including Fgf8. Fgf8, in turn, promotes induction and maintenance of the forkhead box transcription factor FoxG1 (also called brain factor 1, BF1) that is expressed at the early neural plate stages in the prospective telencephalic territory 12,13. Correspondingly, overexpression of Fgf8 by in utero electroporation results in expansion and caudal shift of rostral areas 14, 15, and deletion of FoxG1 leads to a substantial reduction of the telencephalic structures ${ }^{16}$.

Thus, a recurrent model emerges in which the coordinate activity of morphogen gradients initiate and maintain the expression of transcription factors that specify and characterise discrete domains within the CNS. Subsequent dorso-ventral patterning within the telencephalic domain gives rise to pallial and subpallial compartments, the origins of the cerebral cortex and the basal ganglia, respectively.

\subsection{Establishment of dorsal pallial identity}

Although initial specification of the telencephalic territory requires protection from high level Wnt activity, subsequent acquisition of dorsal identity within this domain requires the sequential activation of Wnt and Fgf signalling ${ }^{17}$, together with additional factors such as BMPs and EGFs that may also play instructive roles ${ }^{18}$.

Dorsally located forebrain progenitors become exposed to increasing Wnt signalling activity as development progresses. Firstly, the anterior neural ridge that secretes Wnt 
antagonists at early stages becomes spatially restricted into a small patch of cells at the commissural plate, thus reducing the amount of Wnt antagonists in this region. Secondly, two additional patterning centres arise to establish a dorso-ventral gradient of Wnt signalling (Fig. $1 B, C)$. The cortical hem at the dorsal midline starts to secrete Wnt molecules, whereas the anti-hem, located in the lateral cortex at the level of the pallium/subpallium border, secretes the Wnt antagonist Sfrp2 19-21.

The way in which the Wnt signalling gradient regulates cortical patterning is not completely understood, but it seems to control the expression of transcription factors that promote the acquisition of dorsal identity ${ }^{22}$. Among these transcription factors, Empty spiracles homologue 2 (Emx2), Paired box 6 (Pax6) and Neurogenins (Neurog1 and Neurog2) play crucial roles ${ }^{23-26}$, Emx2 is a direct Wnt signalling target and its expression decreases in $\beta$-catenin loss-of-function mutants ${ }^{27,28}$. Pax6 expression is also altered in a Wnt signaling mutant that carries constitutively active $\beta$-catenin and this mutant also shows expression of Neurog2 in the ventral forebrain and concomitant decrease of ventral markers 28 .

The expression of Emx2 and Pax6 establishes dorsal identity of cortical progenitors and Pax6; Emx2 compound mutants show absence of the cortex and expansion of the ventral domains throughout the telencephalon ${ }^{24}$. Neurog1 and Neurog2 contribute to the dorsal specification of cortical progenitors, as shown by the loss of dorsal marker expression in the cortex of Neurog1; Neurog2 double mutants. Neurog1; Neurog2 mutant cortices also show an up-regulation of ventral markers, such as the Achaete-scute homologue Ascl1 and Distal less Dlx1-2 and $5^{26}$. In addition, a member of the high mobility group of factor, Sox6, has been shown to cooperate with Neurog2 during the specification of dorsal fate ${ }^{29}$. Sox6 regulates pallium-subpallium segregation by repressing the expression of a ventral transcriptional programme in pallial progenitors. Altogether, these studies indicate that these transcription factors predominantly act through inhibition of ventral specification while inducing dorsal fate.

The neocortex, which represents the phylogenetically most recent cortical area, unique to mammals, emerges from the dorsolateral region of the telencephalic vesicles and exhibits a molecular profile distinct from the adjacent medial (archicortex) and lateral (paleocortex) regions. Specification of neocortical identity requires the expression of the LIM homeobox transcription factor Lhx2, which selects neocortical progenitor fate from an already-specified dorsal telencephalic domain, partially by suppressing hem and anti-hem identity in the medial and lateral cortex, respectively ${ }^{30-32}$. 


\subsection{Specification of the ventral telencephalon}

Dorso-ventral specification is acquired as early as E8 in the mouse embryonic telencephalon. Whereas dorsal identity requires the presence of Wnt among other signals, ventral identity is similarly promoted by the combined activities of Sonic hedgehog (Shh), Fgf and possibly retinoic acid signalling ${ }^{33,34}$. Shh is expressed in the prechordal plate at E8 (Fig. 1B), underlying the telencephalic primordium, and later becomes secreted from the hypothalamic anlage and the ventral telencephalon. Here Shh is required for the expression of subpallium restricted transcription factors, such as Dlx1/2, Ascl1 and the homeobox genes Nkx2.1 and Gsx2, whose expression is reduced in Shh mutants ${ }^{35-41}$. Ventral telencephalic structures are completely absent in mutant mice that lack Shh gene ${ }^{42}$, whereas forebrainspecific deletion of Shh signalling from E9 in the mouse leads to early failure of ventral patterning and loss of neurons usually generated from this region ${ }^{39}$, suggesting that Shh activity may control different aspects of subpallium development in addition to initial DV patterning.

The downstream mechanism of Shh activation has been extensively studied in the spinal cord, where differences in Shh concentration and exposure duration determine the balanced activity of Shh target Gli proteins 43,44 . In the telencephalon, Shh is involved in a feedback mechanism with Fgf8 that coordinates the functions of different patterning centres. In the absence of Shh, Gli3 acts as a repressor and inhibits Fgf8 expression; through Gli3mediated de-repression, Shh maintains Fgf8 expression in the anterior neural ridge, and in turn, Fgf8 indirectly induces Shh expression in ventral patterning centres 13, 45, 46. This Shhmediated inhibition of Gli3 repressor function and possibly induction of Gli1 and Gli2 activators in restricted ventral subregions also regulates the pattern of expression of transcription factors like Nkx2.1, Gsx2 and Nkx6.2 35, 37,47 that maintain ventral telencephalic identity and specify ventrally-derived neuronal subpopulations. However, concomitant deletion of Shh and repressor Gli3 successfully rescues the DV patterning defects observed in Shh mutants, indicating that Shh-independent mechanisms may also operate to pattern the ventral telencephalon ${ }^{48}$. Furthermore, Fgf signalling may have ventral specification functions that are independent of Shh. FgfR1/2 double knock-out mice exhibit defects in DV patterning despite normal Shh expression ${ }^{49}$, and Fgf8 overexpression induces ventral markers even in the presence of Shh inhibitors 50. Moreover, both inhibition of Fgf/ERK signalling and compound mutation of either Fgf3/8 or FgfR1/2 results in DV patterning defects with ventral expansion of dorsal markers 49,51,52 (for recent review on Fgf signalling in neural development, refer to ${ }^{53}$ ). Thus, consistent with the model presented previously, ventral 
telencephalic structures are specified through the integrated activity of multiple signalling paths that establish defined patterns of gene expression.

\section{CORTICAL AREALIZATION}

\subsection{Specification of distinct cortical areas}

Although the general pattern of CNS development is conserved throughout evolution, the subsequent elaboration of the dorsal telencephalon has lead to a dramatic expansion of the cerebral cortex during mammalian development 54-56. Cortical progenitors and their neuronal progeny exhibit highly organized spatial distribution, both radially in terms of the laminar microarchitecture (see below) and tangentially in terms of functional subdivisions, also known as arealization ${ }^{57}$.

The four primary functional distinctions include one frontal motor area that controls our movements, and three sensory areas to process auditory, tactile and visual information. The mechanisms that regulate cortical arealization have been the subject of intense debate; the protomap model proposes that patterning is intrinsically encoded in cortical progenitors 58, 59, whereas the protocortex model suggests that thalamic afferent connections that reach the cortex impart specific areal identity through a neuronal activity-dependent event ${ }^{60}$. This has now been reconciled with the recognition that the establishment of cortical area identity begins early in CNS development, even before any functional diversification is apparent, and it is later refined by the formation of neural circuitry 61 .

In the last 15 years the influence of genetic factors on cortical arealization has gained increasing attention and several transcription factors that exhibit cortical patterning activity have been identified (Fig. 2). For example, the combinatorial graded expression of the transcription factors Emx2 and Pax6 determines the formation of distinct progenitor domains along the rostro-caudal axis. Emx2 exhibits a high caudo-medial to low rostro-lateral gradient with Pax6 reciprocally expressed 62,63. Analysis of knockout animals reveals that these counter gradients regulate the relative size of motor (frontal) and sensory (caudal) areas of the cortex. Moreover, Emx2 overexpression induces Pax6 down-regulation in rostral areas and results in a rostro-lateral shift of sensory and motor areas, thus establishing a direct patterning role for Emx2 64 .

Similarly, patterning functions have been ascribed to the orphan nuclear receptor COUP-TFI (also known as Nr2f1) and the Drosophila buttonhead homologue Sp8. COUP-TFI is required for specification of caudal sensory areas 65 , but may also have roles in ventral 
specification during patterning of pallium 66, whereas Sp8 plays a crucial role in the establishment of rostral cortical identity 67,68 . A reciprocal gradient of expression is generated by cross-repressive interaction between Sp8 and COUP-TFI ${ }^{69}$. Indeed, Sp8 mutants exhibit rostral expansion of the caudal marker COUP-TFI 68, whereas cortex-specific deletion of COUP-TFI results in enlarged frontal motor areas at the expense of caudal sensory regions 65.

Furthermore, alterations in cortical area identity observed in the mutants for Emx2, COUP-TFI and Sp8 are paralleled by altered thalamocortical projections that maintain areaspecific connections 62,65,68. Each cortical area receives specific inputs from the principal thalamic nuclei that relay information from subcortical regions. During embryonic and early postnatal development a conserved and stereotyped pattern of connectivity is established between the cortex and the thalamus and can be easily visualized via lipophilic dyes that follow axon tracts. The use of retrograde and anterograde axon tracing reveals that the cortical areas in Emx2, COUP-TFI or SP8 mutants, even if shifted or contracted, maintain areaspecific connections with the thalamus, thus suggesting that a strong genetic pre-patterning is in operation.

\subsection{Establishment of transcription factor domains}

The transcription factor gradients described above are in turn established by the coordinate response of progenitor cells to secreted morphogen signals from various patterning centres located in different antero-posterior, dorso-ventral and medio-lateral positions. For example, Fgf signalling was introduced earlier with a role in initial specification of the telencephalic territory, and several Fgf factors such as Fgf8, Fgf15, Fgf 17 and Fgf18 are secreted from the anterior patterning centers to promote rostral cortical identity ${ }^{70-72}$. Fgf8 controls the expression of several patterning transcription factors, including induction of Sp8 in rostral regions ${ }^{67}$, and the repression of Emx2 and COUP-TFI that become restricted to more caudal regions of the cortex 13, 73. However, distinct Fgf members can differentially regulate COUP-TFI expression and this, in turn, can feedback to refine the region of active Fgf signalling through inhibition of downstream pathways 74 . Fgf17 represses COUP-TFI expression and induces rostral fate, acting similarly to Fgf8 predominantly in the dorsomedial region 75, 76, whereas Fgf15, whose expression extend in the caudal-most region of the ventral pallium ${ }^{77}$ induces COUP-TFI expression and promotes caudal cortical fate ${ }^{78}$. Furthermore, Fgf signalling can be modulated by secreted molecules from other patterning centres ${ }^{18}$. For example, the cortical hem releases members of the BMP and Wnt families that regulate the expression of patterning factors, such as Emx2, through both direct Emx2 transcriptional 
control and indirect modulation of Fgf8 expression 18, 27, 79. Recently, a novel transcription factor, Dmrt5 (double sex and mab3 related) has been shown to promote caudal fate by maintaining Wnt and BMP expression in the cortical hem, thus ultimately inducing Emx2 expression ${ }^{80}$.

Taken together, progenitor cells receive a cocktail of morphogen signals, the relative intensities of which will vary with the relative distance from the secreting patterning centres. Integration of these signalling paths determines a unique signature of transcription factor expression that defines the spatial identity of the progenitor cells; when considered as a progenitor population, this creates the spatial gradients of expression that are described above.

However, these spatial gradients must then be translated into sharp borders of gene expression that demarcate the margins of future cortical areas. The mechanisms underlying this process are not well described in the telencephalon, but studies performed in different contexts indicate that a threshold phenomenon may be involved 1,43; a certain level of transcription factor is required to trigger the activation of a specific set of genes, consequently establishing the limits of target gene expression.

Additionally, a novel framework to explain the segregation of pallial subdivisions has been recently proposed ${ }^{81}$. Pattabiraman and colleagues identified several human enhancers whose activities are restricted to distinct progenitor domains at early developmental stages. By deploying an inducible Cre-mediated approach, the authors followed the fate of the progenitor domains that display single enhancer activity at E11.5; these domains maintain relative spatial locations at later embryonic stages, corresponding to specific regions of the prefrontal cortex. While the pattern of enhancer activity does not exactly match the domain of expression of any single transcription factor, several factors involved in cortical patterning (such as COUPTFI and Pax6), have been shown to bind some of these enhancer elements. Together, these results suggest that the graded expression of different transcription factors may be integrated at the enhancer level to generate distinct patterns of gene activation in different pallial subdivisions.

Downstream of these genomic and genetic factors, various cellular mechanisms may be in place to establish and maintain the areal pattern in the mature cortex. Although these are still poorly understood, several lines of evidence indicate that cell adhesion and cell repulsion molecules might contribute to the segregation of early patterned cortical domains, by promoting differential adhesiveness and cell repulsion at the borders of area subdivisions ${ }^{82}$. Indeed, members of the Cadherin family of adhesive factors and axon guidance molecules of 
the Eph-Ephrin family exhibit restricted patterns of expression in specific cortical areas and they have been used so far as markers for area demarcation 83-87. However, whether these molecules also play a role during the segregation of distinct cortical areas is still unclear. Recent work suggests that Cdh6 may actively function to establish or maintain area identity; Cdh6 expression at early stages demarcates the borders of areas that will only later segregate into functionally distinct cortical regions, such as the barrel field and the limb field 88 .

In the future, it would be interesting to study whether factors like Cadherin and EphEphrins are direct target genes regulated by the patterning transcription factors 81,89 .

\section{NEURONAL DIVERSITY IN THE DORSAL TELENCEPHALON}

\subsection{Progenitor cells within the cerebral cortex}

In addition to the tangential subdivisions, the cerebral cortex is characterised by its histological laminar architecture; six radially arranged layers that are populated by an astonishing variety of neuronal subtypes, each with distinct morphological, hodological and molecular properties in coordination with their final laminar positions 90, 91. For example, corticofugal neurons occupy deep cortical layers V and VI, projecting either to the thalamus or to subcerebral targets such as the spinal cord and the brainstem, and express specific transcription factors including Fezf2, Tbr1 and Sox5 92-95. In contrast, upper layer II-III neurons project to the contralateral hemisphere via the corpus callosum and express transcription factors such as Cux1, Cux2, Satb2 and POU3F3/2 96-100. Moreover, intra-laminar variation of subtype adds further complexity to the vast array of neurons that populate the cortex. One of the key questions in developmental neurobiology is how this neuronal diversification is achieved: are lineage-specific properties imparted at the post-mitotic stage or do fate-restricted progenitors exist in the cortex?

Pioneering transplantation experiments and birth dating studies gave rise to the 'progressive restriction model' 58,101,102. Neurons of lower and upper layers are generated in a temporal order, with final laminar fate determined by neuronal birth date, and progenitor cells becoming restricted in their differentiation potential as development progresses. Accordingly, neurons generated at early developmental stages (e.g prior to E14 in the mouse), differentiate into deep layer V-VI neurons, whereas later born neurons migrate radially and settle into the upper layers II-III-IV, creating an "inside-out" arrangement 103-105 (for recent reviews refer to: ${ }^{91,106}$ ). This model has been predominantly interpreted as a proof for the existence of only one progenitor type that changes and restricts its fate potential over time. 
However, extensive research in the last decade has identified different types of progenitor cells that vary in morphology, mitotic behaviour and molecular profile 107,108 . In rodents, the most abundant neocortical progenitors are radial glia cells (RGCs) and intermediate progenitors (IPCs). RGCs are present from very early stages in mouse development (E9-E10 onwards), dividing at the apical border both symmetrically to self-renew and maintain the pool of progenitors, and asymmetrically to additionally give rise to a more committed neuronal progeny 109,110. IPCs instead divide in more basal regions of the subventricular zone (SVZ), and they do not make contact with the ventricle or the pial surfaces. The accumulation of dividing IPCs in the SVZ starts around E13 and IPCs generally cycle only once or twice before undergoing neurogenic symmetric divisions to produce two post-mitotic neurons ${ }^{111 .}$ Importantly, IPCs produce neurons of all layers, whereas only $10 \%$ of neurons arise directly from RGC differentiation 111,112. More recent works have described the existence of additional progenitor types that exhibit combined RGC and IPC properties ${ }^{113}$. For example, short neural progenitors (SNP) have lost contact with the basal surface but still divide in the ventricular zone (VZ) 114,115, and the newly identified outer radial glia cells (oRG) retract the apical process and divide in more basal regions like IPCs, yet their ability to self-renew and lack of basal marker Tbr2 are properties shared with RGCs 116,117. Most of these progenitor types have been described both in rodents and in humans or non-human primates. However their relative abundance varies according to the species. In humans, the impact of oRG cell proliferation on neuronal output is much greater than in mice (oRGs in rodents represent only $6 \%$ of all murine cortical progenitors, whereas in humans oRG cells represent $40 \%$ of the progenitors in the outer SVZ117, 118), and it contributes to the tangential expansion of the gyrencepahlic neocortex ${ }^{55}$. Although these progenitor types show differences in morphology and spatial locations, it is unclear whether they also differ in fate potential and preferentially give rise to specific neuronal subpopulations.

An alternative approach has characterised transcription factors that are expressed in progenitor cells and subsequently maintained in layer and neuron subtype-specific postmitotic neurons, making them attractive candidates to specify neuronal subtypes. Among them, the zinc finger transcription factor Fezf2 and the orthodenticle homologue 1 (Otx1) are expressed in the VZ progenitors at the time of deep layer neuron generation, and these same factors are later maintained in post-mitotic layer V and VI neurons 92, 93, 119, 120. Similarly, Lhx2 is expressed both in progenitors and in the upper layer neurons that originate from them ${ }^{31}$, 121. Nevertheless, these factors may not be directly involved in the specification of deep or superficial-layer neurons, and indeed, recent lineage tracing experiments have shown that 
Fezf2-positive RGCs are multipotent progenitors that differentiate into neurons of all cortical layers and into glial cells ${ }^{122}$. This is consistent with clonal analysis, showing that clonally labelled radial glia cells give rise over time to neurons of different layers within the same columnar unit 102,123-125.

Interestingly, a lineage association has been reported for the transcription factor, Cut like 2 (Cux2) ${ }^{126}$. Franco and colleagues developed an inducible lineage tracing technique to show that only Cux2 positive progenitors give rise to Satb2 positive upper layer neurons, and Cux2 negative cells instead generate deep layer neurons, demonstrating that a lineage relationship exists between fate-restricted progenitors and layer-specific neurons. Moreover, although upper layer neurons are generally born at late developmental stages, Cux2 positive progenitors have been detected also at early time points, even before the onset of upper layer neuron generation. Indeed, forced cell cycle exit and differentiation of Cux2 positive cells at very early time points gives rise to correctly specified upper layer neurons, indicating that neuronal fate is primarily governed by intrinsic determinants and not by the time of birth ${ }^{126}$.

This view is, however, controversial and contrasts with other available data. For example a lineage tracing approach similar to the one employed by Franco et al revealed that Cux2 positive cells also populate lower layers and express Ctip2, a marker of lower layer neurons ${ }^{122}$. It is important to note though that the analysis showing Cux2 contribution to lower cortical layers was performed only at an early postnatal stage (P0) when the cortical layers are still intermingled and cells are still migrating. Therefore analysis at a later stage is needed to strengthen the conclusion that Cux2 positive cells contribute to all layers of the cortex.

Additional evidence that challenges the view of Cux2 as a fate determinant of upper layer neuron identity in progenitors comes from the analysis of Cux2 null mutants, in which upper layers are not lost but expanded, and upper layer neurons are correctly specified ${ }^{127 .}$ Therefore, further work is needed to clarify the role of Cux2 in neuronal subtype specification and the existence of Cux2 positive (and/or Cux2 negative) fate-restricted progenitors in the cortex ${ }^{128}$.

\subsection{Mechanisms of generating cortical progenitor diversification}

A related field of investigation is directed towards elucidating the mechanisms of progenitor diversification. So far only a few signals and factors have been identified that can differentially influence the fate or cell cycle properties of specific cortical progenitors. From the discussion above it is clear that progenitors in distinct locations and/or at different 
developmental stages may be subjected to diverse environmental cues that instruct their fate. It has been proposed that temporal restriction in progenitor fate potential may be caused not by intrinsic limitations, but by progressive changes in the extracellular environment that supports the proliferation and differentiation of distinct progenitors over time 106. For example, lower layer neurons, which are the first to populate the cortical plate, release soluble factors like Nt3 and members of the Fgf family (Fgf18, Fgf9) that feed back to the VZ progenitors and switch them to the production of the next neocortical layer and glial cells ${ }^{129}$, 130.

Direct cell-cell communication via Notch signalling may also be influential in progenitor cell fate; the expression of Notch ligands in IPCs and neuroblasts activates Notch signalling in RGCs to maintain them as progenitors 131,132. Although differences in Notch signalling among RGCs during early or late neurogenesis have not been described, it has been proposed that Notch activation may primarily induce proliferation of RGCs during early neurogenesis, so that the progenitors of upper layer neurons expand during lower layer neurogenesis 106. Intrinsic cell cycle programs and morphological properties, such as directional protrusions, can also contribute to the differential reception of the above signals. For example, the basal process that spans the entire cortical plate enables RGCs and oRGs to sense signals such as Notch ligands that promote self-renewing divisions 118, 133, 134. Differences in Notch activation may also stem from asymmetrical inheritance of fate determinants that govern the fate of the daughter cells after cell division. Polarity complexes, such Par3/aPKC regulate the distribution of intracellular components of the Notch signalling pathway (Mindbomb, Numb and Numb-like) and they also determine which cell will inherit the apical or the basal process 133,135. Additional pro-differentiative signals, such as retinoic acid and BMP7, are released from the meninges on the outer surface of the brain, possibly influencing the fate of cells that possess the basal process. However, how these signals can differentially affect progenitor lineage-restriction or the cell cycle properties is currently unknown.

Furthermore, in contrast to IPCs and oRGs, RGCs also contact the ventricular surface at the apical side and extend a primary cilium into the lateral ventricles that are filled with the corticospinal fluid (CSF). Proteomic analysis of the CSF has identified Igf2, a growth factor that binds to the Igf receptor localized to RGC cilia ${ }^{136}$. Interestingly, Igf2 is enriched at late stages of neurogenesis and specifically promotes the differentiation of late-born upper layer neurons, as demonstrated by the selective decrease in this neuronal population in Igf2 knockouts. 
Therefore, the different morphological properties displayed by distinct progenitor types may underlie their capacity to sense and respond to environmental cues coming from the extracellular milieu. Further studies will be important to understand the contribution of different signals to the restriction of progenitor fate potential.

\section{NEURONAL DIVERSITY IN THE VENTRAL TELENCEPHALON}

\subsection{Progenitor cells within the subpallium}

The subpallium is the site of origin of multiple neuronal types that principally occupy the ventral telencephalic structures of the striatum, globus pallidus and other nuclei within the basal ganglia. The striatum is largely composed of the GABAergic medium-sized spiny projection neurons (MSNs) that receive cortical input and target other ventral forebrain nuclei to process motor and cognitive information 137, 138. In addition to MSNs, distinct subtypes of GABAergic and cholinergic interneurons also settle in the striatum and modulate the activity of MSNs. The basal forebrain gives rise not only to neurons that remain within the ventral structures, but also to a large variety of GABAergic interneurons that migrate long distances to populate the cortex and the olfactory bulb 139-141.

In contrast to neurogenesis in the dorsal pallium, it is well established that each neuronal subtype originates from different progenitors located in discrete domains of the subpallial VZ (Fig. 3). A primary subdivision of the subpallium occurs early in development with the formation of three evaginations, the ganglionic eminences (GEs), in the lateral (LGE), medial (MGE) and caudal (CGE) positions. Early transplantation studies and recent fate mapping experiments revealed that the LGE is the major source of striatal MSNs and of olfactory interneurons, whereas the MGE and CGE generate the majority of the cortical interneurons 142, 143. Each domain expresses a precise combination of transcription factors that play instructive roles in the specification of the distinct neuronal subtypes.

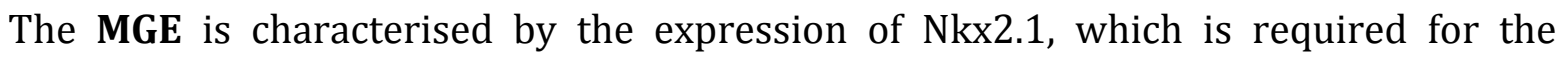
generation of GABAergic cortical interneurons and for the suppression of alternative cell fates 144, 145. Gene expression profiling of the MGE reveals a high degree of heterogeneity of the Nkx2.1 positive domain, indicating that further subdivisions of the MGE exist 146, 147. It is possible that distinct combinations of transcription factors in each of these MGE subregions may define fate-restricted progenitors that will give rise to specific interneuron subpopulations. For example, coexpression of Nkx2.1 with Nkx6.2 in the most dorsal part of 
the MGE, has been shown to induce the specific generation of calretinin (CR)+ and somatostatin (SST)+ non-fast spiking Martinotti interneurons 148, 149 .

Within the single population of cortical GABAergic interneurons derived from the Nkx2.1-positive and Nkx6.2-negative domain, there is an astonishing variety of subtypes, distinguished by unique combinations of neurochemical, morphological and electrophysiological properties 150,151. As in the neocortex, we have little understanding of how this high degree of neuronal diversity is achieved in the ventral telencephalon.

Progenitor types with distinct morphologies have been identified in the subpallium (RGC, SNP, IP and the newly described SAP ${ }^{152}$ ) (for recent reviews refer to: ${ }^{108}$ ). However it is currently unknown whether these represent distinct subtype-restricted progenitors. Fate mapping studies and electrophysiological analysis point towards the existence of one progenitor that changes fate potential for discrete interneuron subtypes over time ${ }^{142,153}$. This is consistent with early birth-dating experiments, showing that early born interneurons preferentially populate deep cortical layers where age-matched cortical projection neurons are located, whereas later-born interneurons mainly settle into more superficial layers ${ }^{154-156 .}$ Recent clonal analyses also support the temporal generation of distinct interneuron subtypes 157, 158. Interestingly, clonally related or synchronously born interneurons tend to cluster together once they reach the cortex, suggesting that some aspects of the final functional organization of inhibitory interneurons in the cortex are established at the progenitor level.

A key transcription factor known to act downstream of Nkx2.1 in the regulation of cortical interneuron specification and migration is the homeodomain protein Lhx6 159-161. Similar to Nkx2.1 deletion, loss of Lhx6 results in a reduced number of MGE-derived GABAergic interneurons in both the cortex (parvalbumin-PV+ and SST+) and striatum 159, 161. Moreover, Lhx6 expression in the MGE has been shown to identify a bi-potent common precursor for both GABAergic and cholinergic striatal interneurons ${ }^{162}$. As development progresses, subsequent expression of Lhx7 and Isl1 down-regulates Lhx6 and specifies cholinergic identity, whereas the maintenance of Lhx6 expression induces GABAergic fate. Lhx7 and Isl1 interact to bind to cholinergic genes, such as acetylcholine synthetizing enzyme (Acly) and transporters (ChAT) ${ }^{163}$ and the striatum of Lhx7 null mutants exhibits a strong reduction in ChAT+ Isl1+ cells, with a concomitant increase in GABAergic Lhx6 positive interneurons ${ }^{159}$. Indeed, in both full 159 and ChAT-Cre ${ }^{164}$ conditional Lhx7 knockouts, the committed precursors for cholinergic interneurons switch fate in the absence of Lhx7 and differentiate towards GABAergic interneurons of the striatum. Not only does this suggest the 
presence of a common bipotent progenitor that is biased towards the GABAergic fate, but also emphasises the plasticity of progenitor fate specification after initial commitment.

Progenitors located in the LGE are instead characterised by high expression of Gsx2, which has distinct temporal and spatial roles in the production of striatal projection neurons and olfactory bulb interneurons ${ }^{165}$. Gain and loss of Gsx2 function experiments performed at different embryonic time points, reveal that Gsx2 promotes the acquisition of striatal interneuron identity at early stages, and that of olfactory interneurons at later stages. Moreover, the combinatorial expression of Gsx2 with other transcription factors that are spatially segregated in subregions of the LGE ultimately define the transcriptional code required for the specification of these two molecularly distinct neuronal subtypes 146 .

For example, the most dorsal part of the LGE produces olfactory interneurons and exhibits the highest Gsx2 expression together with selective expression of Er81. In contrast, ventral LGE progenitors express lower Gsx2 levels together with the transcription factor Isl1, predominantly forming striatal interneurons $165,166$.

In addition to Gsx2, the related protein Gsx1 contributes to establish LGE identity, as shown by the more severe disruption in striatal and olfactory development in the double Gsx1/Gsx2 mutants, in comparison to Gsx2 single mutant 167. However, Gsx1 and Gsx2 exhibit distinct roles in the balance between proliferation and differentiation of LGE progenitors; Gsx2 is uniquely required for the expansion of LGE progenitors, thus coordinating the growth of the progenitor pool in the LGE with the specification of its progeny 168 .

The molecular identity of the CGE has been more difficult to define, since the CGE represents an extension of the LGE in the more caudal brain regions without a clear anatomical boundary. Similar to the LGE, the CGE also expresses transcription factors such as Gsx2 and Er81, but in contrast to the LGE, where Gsx2 specifies striatal or olfactory interneurons, in the CGE, Gsx2 positive progenitors give rise to a discrete subpopulation of interneurons destined to the cerebral cortex ${ }^{148}$. In fact, the CGE contribute to $30 \%$ of all cortical interneurons, although the major source remains the MGE 142, 169. CGE-derived interneurons express different markers than MGE-derived cells and the majority of these neurons migrate to more caudal cortical regions. Interestingly, neural precursors in the CGE lack the expression of the MGE-specific factor Lhx6 and instead selectively express COUPTFII, which has been shown to also impart caudal migratory properties ${ }^{170}$. The identification of 
additional CGE-restricted factors will contribute to our understanding of cortical interneuron diversification.

Altogether, these studies demonstrate the existence of several discrete domains of gene expression in the subpallial VZ that identify distinct types of fate-committed progenitors. Such domains of gene expression create molecular boundaries that go beyond the primary anatomical divisions and further subdivide the classical MGE, LGE and CGE into subregions expressing distinctive combinations of fate-determining transcription factors.

\subsection{Mechanisms of subpallial progenitor diversification: a role for Shh}

A question that still attracts the interest of many researchers is how distinct gene expression domains and diversification among neural progenitors arise. Once again, we revisit the concept of morphogen signals, secreted from early patterning centres, which may contribute to the formation of specific molecular identities that are then maintained by crossrepressive interactions among transcription factors.

As discussed above, one of the most studied factors in DV patterning is Shh. Early expression of Shh in the prechordal plate underlying the telencephalic primordium, initially leads to the formation of a sharp boundary between the dorsal Pax6 domain and the ventral Nkx2.1 domain, by repressing Pax6 and by promoting Nkx2.1 expression in the ventral forebrain 12, 39, 171. Later in development, around E10 in the mouse, Shh-dependent and independent mechanisms induce the expression of the transcription factor Gsx2 between the Pax6 and the Nkx2.1 domains, thus marking the prospective LGE/CGE regions ${ }^{172}$. In addition, Shh expression in the MGE domain is required to prevent ectopic expression of Gsx2, thus preventing LGE identity conversion in MGE progenitors ${ }^{37}$.

Continued Shh signaling is required to maintain Nkx2.1 expression in MGE progenitors. In turn, Nkx2.1 and the downstream transcriptional cascade mediated by Lhx6 and Lhx7 subsequently contribute to maintenance of Shh expression in the mantle zone of the ventral MGE, thus creating a positive feedback that promotes MGE progenitor development 36,173.

It has been proposed that the levels of Shh influence the diversity of MGE-derived interneurons ${ }^{37}$. In vitro stimulation of MGE explants with high Shh concentrations leads to the generation of SST positive cells, whereas lower Shh concentrations induce PV fate. These results are consistent with earlier transplantation studies demonstrating the existence of a spatial bias within the MGE for the production of SST and PV positive interneurons ${ }^{147}$. 
However, a major difference arises from these studies, since PV cells that are produced in vitro at low Shh concentrations, are preferentially generated in vivo from the ventral MGE, which would likely be exposed to higher Shh levels due to Shh expression in the most ventral regions of the forebrain. Similarly, SST positive cells that originate under stimulation with high Shh concentrations in vitro are predominantly produced in vivo in the dorsal MGE, which is located at a greater distance from the area of higher Shh expression. Interestingly, in contrast to Shh expression itself, it has been shown that the downstream activation of Shh effectors and target genes is higher in the more dorsal part of the MGE, in the interganglionic sulcus 146,147. This anomaly can be explained by potential differences in Shh availability and diffusion, which may be distorted by the presence of specific extracellular matrix components and/or by differences in progenitor competence to respond to Shh signalling. Indeed, progenitors in the ventral MGE lack the expression of the Gli activators and it is possible that Shh stimulation of these progenitors dampens responsiveness to Shh itself to prevent a selfreinforcing loop ${ }^{33}$.

\section{CONCLUSION}

The neurodevelopmental processes that transform the single layered neuroepithelium into the complex structure of the adult brain have been subject of fascination and research investigation for many years now. Since the first beautiful drawings of Ramon y Cajal we have come a long way in describing the variety of neuronal types that populate the CNS and connect to each other to form functional circuitries. Technical advances in lineage tracing analysis and in genetic manipulation of the embryonic brain in vivo via in utero electroporation contributed strongly to the rapid accumulation of knowledge on how neuronal diversity is achieved. Similar mechanisms of embryonic patterning are sometimes shared in different CNS regions, such as the ventral telencephalon and spinal cord, where clear boundaries of gene expression mark distinct progenitor domains that will give rise to specific neuronal subpopulations. However, distinct and still poorly understood mechanisms determine neuronal diversity in the dorsal pallium, where the presence of fate-restricted progenitors has just begun to be explored.

Specification of cell fate requires strict coordination of extrinsic positional information and intrinsic state of progenitor competence, both of which may undergo temporal changes as development progresses. 
Studies performed on neural progenitors cultured in vitro have challenged some of the key concepts of neural differentiation; reprogramming of fibroblast cells into neurons revealed a high degree of plasticity in cell fate choices, which were initially believed to be irreversible 174,175. Also, in vitro cultures of cortical neuron precursors have been shown to recapitulate the sequential generation of projection neurons observed in vivo, suggesting that environmental cues of the in vivo niche may play only secondary roles in cell fate switches in progenitor cells ${ }^{176}$. Future studies will be aimed at understanding the contribution and coordination of genetic and environmental factors in neuronal specification, in order to exploit this knowledge to drive pluripotent stem cells towards therapeutically relevant neuronal subtypes. The intersection between basic developmental neurobiology and stem cell biology will be an exciting field of research that to our view holds the key for regenerative medicine in neurodegenerative diseases.

\section{FIGURE LEGENDS}

\section{Figure 1: Early telencephalic patterning and patterning centres}

(A) Schematic view of the developing neural tube, showing the main subdivisions. A series of vesicles later give rise to the structures within the forebrain, midbrain and hindbrain, with the telencephalic territory being specified in the most rostral regions of the prosencephalon.

(B) Expansion and folding of the cephalic end of the neural tube determine the formation of the cerebral hemispheres. Neural progenitor cells within the telencephalon acquire a positional identity through the concerted action of patterning centres that release various morphogen signals. The Hem, Anti-Hem, Prechordal plate and Anterior Neural Ridge (ANR) are illustrated on the diagram, along with examples of secreted morphogens as described in the main text.

(C) Coronal section of the forebrain, illustrating the location of the Hem and Anti-Hem in relation to the developing dorsal and ventral telencephalon. These regions are characterised by differential expression of transcription factors that are indicated on the right.

\section{Figure 2: Cortical arealisation and graded expression of transcription factors}

(A) Schematic representation of the relative size and position of the four main functional areas of the cortex. M1: motor; S1: somatosensory; A1: auditory; V1: primary visual cortex.

(B) Schematic view of the developing telencephalon, illustrating the gradient of expression of four transcription factors with patterning activity. Emx2-Pax6 and COUPTFI-SP8 exhibit 
overlapping counter-gradients that establish cortical area identities along the major spatial axes. A: anterior; P: posterior; L: lateral; M: medial.

(C) Summary of the changes in area patterning observed in genetic knock-out animals of the specified transcription factors. See text for details and references.

\section{Figure 3: Development of the ventral forebrain}

(A) Basic organization of the embryonic brain to illustrate the spatial location of the medial (MGE), lateral (LGE) and caudal (CGE) ganglionic eminences. Anterior and posterior crosssections of the forebrain are shown in B and C, respectively.

(B) Coronal view of one cerebral hemisphere at a rostral level, illustrating the medio-lateral position of the LGE and MGE. Differential expression of transcription factors between GEs and within GEs is illustrated by different colour codes. These regions ultimately generate different neuronal populations, as indicated in the text below the figures.

(C) Cross sectional view of one cerebral hemisphere at a caudal level, showing the site of origin of $30 \%$ of cortical interneurons.

Acknowledgements: work in AP lab is supported by Medical Research Council (MRC) grants G0700758 and MR/K018329/1 and Doctoral Training Award (LH); RA is supported by an MRC postdoctoral fellowship.

1. Briscoe J, Novitch BG. Regulatory pathways linking progenitor patterning, cell fates and neurogenesis in the ventral neural tube. Philos Trans $R$ Soc Lond B Biol Sci 2008, 363:57-70.

2. Rallu M, Corbin JG, Fishell G. Parsing the prosencephalon. Nat Rev Neurosci 2002, 3:943-951.

3. Durston AJ, Timmermans JP, Hage WJ, Hendriks HF, de Vries NJ, Heideveld M, Nieuwkoop PD. Retinoic acid causes an anteroposterior transformation in the developing central nervous system. Nature 1989, 340:140-144.

4. Braun MM, Etheridge A, Bernard A, Robertson CP, Roelink H. Wnt signaling is required at distinct stages of development for the induction of the posterior forebrain. Development 2003, 130:5579-5587.

5. Andoniadou CL, Martinez-Barbera JP. Developmental mechanisms directing early anterior forebrain specification in vertebrates. Cell Mol Life Sci 2013, 70:3739-3752.

6. Andoniadou CL, Signore M, Sajedi E, Gaston-Massuet C, Kelberman D, Burns AJ, Itasaki N, Dattani M, Martinez-Barbera JP. Lack of the murine homeobox gene Hesx1 leads to a posterior transformation of the anterior forebrain. Development 2007, 134:1499-1508.

7. Andoniadou CL, Signore M, Young RM, Gaston-Massuet C, Wilson SW, Fuchs E, Martinez-Barbera JP. HESX1- and TCF3-mediated repression of Wnt/beta-catenin targets is required for normal development of the anterior forebrain. Development 2011, 138:4931-4942. 
8. Carlin D, Sepich D, Grover VK, Cooper MK, Solnica-Krezel L, Inbal A. Six3 cooperates with Hedgehog signaling to specify ventral telencephalon by promoting early expression of Foxg1a and repressing Wnt signaling. Development 2012, 139:26142624.

9. Lagutin OV, Zhu CC, Kobayashi D, Topczewski J, Shimamura K, Puelles L, Russell HR, McKinnon PJ, Solnica-Krezel L, Oliver G. Six3 repression of Wnt signaling in the anterior neuroectoderm is essential for vertebrate forebrain development. Genes Dev 2003, 17:368-379.

10. Martinez-Barbera JP, Rodriguez TA, Beddington RS. The homeobox gene Hesx1 is required in the anterior neural ectoderm for normal forebrain formation. Dev Biol 2000, 223:422-430.

11. Hoch RV, Rubenstein JL, Pleasure S. Genes and signaling events that establish regional patterning of the mammalian forebrain. Semin Cell Dev Biol 2009, 20:378-386.

12. Shimamura K, Rubenstein JL. Inductive interactions direct early regionalization of the mouse forebrain. Development 1997, 124:2709-2718.

13. Storm EE, Garel S, Borello U, Hebert JM, Martinez S, McConnell SK, Martin GR, Rubenstein JL. Dose-dependent functions of Fgf8 in regulating telencephalic patterning centers. Development 2006, 133:1831-1844.

14. Fukuchi-Shimogori T, Grove EA. Neocortex patterning by the secreted signaling molecule FGF8. Science 2001, 294:1071-1074.

15. Toyoda R, Assimacopoulos S, Wilcoxon J, Taylor A, Feldman P, Suzuki-Hirano A, Shimogori T, Grove EA. FGF8 acts as a classic diffusible morphogen to pattern the neocortex. Development 2010, 137:3439-3448.

16. Xuan S, Baptista CA, Balas G, Tao W, Soares VC, Lai E. Winged helix transcription factor BF-1 is essential for the development of the cerebral hemispheres. Neuron 1995, 14:1141-1152.

17. Gunhaga L, Marklund M, Sjodal M, Hsieh JC, Jessell TM, Edlund T. Specification of dorsal telencephalic character by sequential Wnt and FGF signaling. Nat Neurosci 2003, 6:701-707.

18. Shimogori T, Banuchi V, Ng HY, Strauss JB, Grove EA. Embryonic signaling centers expressing BMP, WNT and FGF proteins interact to pattern the cerebral cortex. Development 2004, 131:5639-5647.

19. Houart C, Caneparo L, Heisenberg C, Barth K, Take-Uchi M, Wilson S. Establishment of the telencephalon during gastrulation by local antagonism of Wnt signaling. Neuron 2002, 35:255-265.

20. Assimacopoulos S, Grove EA, Ragsdale CW. Identification of a Pax6-dependent epidermal growth factor family signaling source at the lateral edge of the embryonic cerebral cortex. J Neurosci 2003, 23:6399-6403.

21. Subramanian L, Remedios R, Shetty A, Tole S. Signals from the edges: the cortical hem and antihem in telencephalic development. Semin Cell Dev Biol 2009, 20:712-718.

22. Harrison-Uy SJ, Pleasure SJ. Wnt signaling and forebrain development. Cold Spring Harb Perspect Biol 2012, 4:a008094.

23. Muzio L, Di Benedetto B, Stoykova A, Boncinelli E, Gruss P, Mallamaci A. Emx2 and Pax6 control regionalization of the pre-neuronogenic cortical primordium. Cereb Cortex 2002, 12:129-139.

24. Muzio L, DiBenedetto B, Stoykova A, Boncinelli E, Gruss P, Mallamaci A. Conversion of cerebral cortex into basal ganglia in Emx2(-/-) Pax6(Sey/Sey) double-mutant mice. Nat Neurosci 2002, 5:737-745.

25. Muzio L, Mallamaci A. Emx1, emx2 and pax6 in specification, regionalization and arealization of the cerebral cortex. Cereb Cortex 2003, 13:641-647. 
26. Fode C, Ma Q, Casarosa S, Ang SL, Anderson DJ, Guillemot F. A role for neural determination genes in specifying the dorsoventral identity of telencephalic neurons. Genes Dev 2000, 14:67-80.

27. Theil T, Aydin S, Koch S, Grotewold L, Ruther U. Wnt and Bmp signalling cooperatively regulate graded Emx2 expression in the dorsal telencephalon. Development 2002, 129:3045-3054.

28. Backman M, Machon O, Mygland L, van den Bout CJ, Zhong W, Taketo MM, Krauss S. Effects of canonical Wnt signaling on dorso-ventral specification of the mouse telencephalon. Dev Biol 2005, 279:155-168.

29. Azim E, Jabaudon D, Fame RM, Macklis JD. SOX6 controls dorsal progenitor identity and interneuron diversity during neocortical development. Nat Neurosci 2009, 12:1238-1247.

30. Mangale VS, Hirokawa KE, Satyaki PR, Gokulchandran N, Chikbire S, Subramanian L, Shetty AS, Martynoga B, Paul J, Mai MV, et al. Lhx2 selector activity specifies cortical identity and suppresses hippocampal organizer fate. Science 2008, 319:304-309.

31. Monuki ES, Porter FD, Walsh CA. Patterning of the dorsal telencephalon and cerebral cortex by a roof plate-Lhx2 pathway. Neuron 2001, 32:591-604.

32. Chou SJ, Perez-Garcia CG, Kroll TT, O'Leary DD. Lhx2 specifies regional fate in Emx1 lineage of telencephalic progenitors generating cerebral cortex. Nat Neurosci 2009, 12:1381-1389.

33. Sousa VH, Fishell G. Sonic hedgehog functions through dynamic changes in temporal competence in the developing forebrain. Curr Opin Genet Dev 2010, 20:391-399.

34. Ribes V, Wang Z, Dolle P, Niederreither K. Retinaldehyde dehydrogenase 2 (RALDH2)mediated retinoic acid synthesis regulates early mouse embryonic forebrain development by controlling FGF and sonic hedgehog signaling. Development 2006, 133:351-361.

35. $\mathrm{Xu} \mathrm{Q}$, Wonders $\mathrm{CP}$, Anderson SA. Sonic hedgehog maintains the identity of cortical interneuron progenitors in the ventral telencephalon. Development 2005, 132:49874998.

36. Flandin P, Zhao Y, Vogt D, Jeong J, Long J, Potter G, Westphal H, Rubenstein JL. Lhx6 and Lhx8 coordinately induce neuronal expression of Shh that controls the generation of interneuron progenitors. Neuron 2011, 70:939-950.

37. Xu Q, Guo L, Moore H, Waclaw RR, Campbell K, Anderson SA. Sonic hedgehog signaling confers ventral telencephalic progenitors with distinct cortical interneuron fates. Neuron 2010, 65:328-340.

38. Ericson J, Muhr J, Placzek M, Lints T, Jessell TM, Edlund T. Sonic hedgehog induces the differentiation of ventral forebrain neurons: a common signal for ventral patterning within the neural tube. Cell 1995, 81:747-756.

39. Fuccillo M, Rallu M, McMahon AP, Fishell G. Temporal requirement for hedgehog signaling in ventral telencephalic patterning. Development 2004, 131:5031-5040.

40. Kohtz JD, Baker DP, Corte G, Fishell G. Regionalization within the mammalian telencephalon is mediated by changes in responsiveness to Sonic Hedgehog. Development 1998, 125:5079-5089.

41. Gunhaga L, Jessell TM, Edlund T. Sonic hedgehog signaling at gastrula stages specifies ventral telencephalic cells in the chick embryo. Development 2000, 127:3283-3293.

42. Chiang C, Litingtung Y, Lee E, Young KE, Corden JL, Westphal H, Beachy PA. Cyclopia and defective axial patterning in mice lacking Sonic hedgehog gene function. Nature 1996, 383:407-413.

43. Cohen M, Briscoe J, Blassberg R. Morphogen interpretation: the transcriptional logic of neural tube patterning. Curr Opin Genet Dev 2013, 23:423-428. 
44. Balaskas N, Ribeiro A, Panovska J, Dessaud E, Sasai N, Page KM, Briscoe J, Ribes V. Gene regulatory logic for reading the Sonic Hedgehog signaling gradient in the vertebrate neural tube. Cell 2012, 148:273-284.

45. Rash BG, Grove EA. Patterning the dorsal telencephalon: a role for sonic hedgehog? J Neurosci 2007, 27:11595-11603.

46. Hayhurst M, Gore BB, Tessier-Lavigne M, McConnell SK. Ongoing sonic hedgehog signaling is required for dorsal midline formation in the developing forebrain. Dev Neurobiol 2008, 68:83-100.

47. Yu W, Wang Y, McDonnell K, Stephen D, Bai CB. Patterning of ventral telencephalon requires positive function of Gli transcription factors. Dev Biol 2009, 334:264-275.

48. Rallu M, Machold R, Gaiano N, Corbin JG, McMahon AP, Fishell G. Dorsoventral patterning is established in the telencephalon of mutants lacking both Gli3 and Hedgehog signaling. Development 2002, 129:4963-4974.

49. Gutin G, Fernandes M, Palazzolo L, Paek H, Yu K, Ornitz DM, McConnell SK, Hebert JM. FGF signalling generates ventral telencephalic cells independently of SHH. Development 2006, 133:2937-2946.

50. Kuschel S, Ruther U, Theil T. A disrupted balance between Bmp/Wnt and Fgf signaling underlies the ventralization of the Gli3 mutant telencephalon. Dev Biol 2003, 260:484495.

51. Shinya M, Koshida S, Sawada A, Kuroiwa A, Takeda H. Fgf signalling through MAPK cascade is required for development of the subpallial telencephalon in zebrafish embryos. Development 2001, 128:4153-4164.

52. Walshe J, Mason I. Unique and combinatorial functions of Fgf3 and Fgf8 during zebrafish forebrain development. Development 2003, 130:4337-4349.

53. Guillemot F, Zimmer C. From cradle to grave: the multiple roles of fibroblast growth factors in neural development. Neuron 2011, 71:574-588.

54. Borrell V, Reillo I. Emerging roles of neural stem cells in cerebral cortex development and evolution. Dev Neurobiol 2012, 72:955-971.

55. Lui JH, Hansen DV, Kriegstein AR. Development and evolution of the human neocortex. Cell 2011, 146:18-36.

56. Rakic P. Evolution of the neocortex: a perspective from developmental biology. Nat Rev Neurosci 2009, 10:724-735.

57. O'Leary DD, Sahara S. Genetic regulation of arealization of the neocortex. Curr Opin Neurobiol 2008, 18:90-100.

58. Rakic P. Specification of cerebral cortical areas. Science 1988, 241:170-176.

59. O'Leary DD, Borngasser D. Cortical ventricular zone progenitors and their progeny maintain spatial relationships and radial patterning during preplate development indicating an early protomap. Cereb Cortex 2006, 16 Suppl 1:i46-56.

60. O'Leary DD. Do cortical areas emerge from a protocortex? Trends Neurosci 1989, 12:400-406.

61. Sur M, Rubenstein JL. Patterning and plasticity of the cerebral cortex. Science 2005, 310:805-810.

62. Bishop KM, Goudreau G, O'Leary DD. Regulation of area identity in the mammalian neocortex by Emx2 and Pax6. Science 2000, 288:344-349.

63. Bishop KM, Rubenstein JL, O'Leary DD. Distinct actions of Emx1, Emx2, and Pax6 in regulating the specification of areas in the developing neocortex. J Neurosci 2002, 22:7627-7638.

64. Hamasaki T, Leingartner A, Ringstedt T, O'Leary DD. EMX2 regulates sizes and positioning of the primary sensory and motor areas in neocortex by direct specification of cortical progenitors. Neuron 2004, 43:359-372. 
65. Armentano M, Chou SJ, Tomassy GS, Leingartner A, O'Leary DD, Studer M. COUP-TFI regulates the balance of cortical patterning between frontal/motor and sensory areas. Nat Neurosci 2007, 10:1277-1286.

66. Faedo A, Tomassy GS, Ruan Y, Teichmann H, Krauss S, Pleasure SJ, Tsai SY, Tsai MJ, Studer M, Rubenstein JL. COUP-TFI coordinates cortical patterning, neurogenesis, and laminar fate and modulates MAPK/ERK, AKT, and beta-catenin signaling. Cereb Cortex 2008, 18:2117-2131.

67. Sahara S, Kawakami Y, Izpisua Belmonte JC, O'Leary DD. Sp8 exhibits reciprocal induction with Fgf8 but has an opposing effect on anterior-posterior cortical area patterning. Neural Dev 2007, 2:10.

68. Zembrzycki A, Griesel G, Stoykova A, Mansouri A. Genetic interplay between the transcription factors Sp8 and Emx2 in the patterning of the forebrain. Neural Dev 2007, 2:8.

69. Borello U, Madhavan M, Vilinsky I, Faedo A, Pierani A, Rubenstein J, Campbell K. Sp8 and COUP-TF1 reciprocally regulate patterning and Fgf signaling in cortical progenitors. Cereb Cortex 2014, 24:1409-1421.

70. McWhirter JR, Goulding M, Weiner JA, Chun J, Murre C. A novel fibroblast growth factor gene expressed in the developing nervous system is a downstream target of the chimeric homeodomain oncoprotein E2A-Pbx1. Development 1997, 124:3221-3232.

71. Maruoka Y, Ohbayashi N, Hoshikawa M, Itoh N, Hogan BL, Furuta Y. Comparison of the expression of three highly related genes, Fgf8, Fgf17 and Fgf18, in the mouse embryo. Mech Dev 1998, 74:175-177.

72. Bachler M, Neubuser A. Expression of members of the Fgf family and their receptors during midfacial development. Mech Dev 2001, 100:313-316.

73. Garel S, Huffman KJ, Rubenstein JL. Molecular regionalization of the neocortex is disrupted in Fgf8 hypomorphic mutants. Development 2003, 130:1903-1914.

74. Faedo A, Borello U, Rubenstein JL. Repression of Fgf signaling by sprouty1-2 regulates cortical patterning in two distinct regions and times. J Neurosci 2010, 30:4015-4023.

75. Cholfin JA, Rubenstein JL. Frontal cortex subdivision patterning is coordinately regulated by Fgf8, Fgf17, and Emx2. J Comp Neurol 2008, 509:144-155.

76. Cholfin JA, Rubenstein JL. Patterning of frontal cortex subdivisions by Fgf17. Proc Natl Acad Sci U S A 2007, 104:7652-7657.

77. Gimeno L, Brulet P, Martinez S. Study of Fgf15 gene expression in developing mouse brain. Gene Expr Patterns 2003, 3:473-481.

78. Borello U, Cobos I, Long JE, McWhirter JR, Murre C, Rubenstein JL. FGF15 promotes neurogenesis and opposes FGF8 function during neocortical development. Neural Dev 2008, 3:17.

79. Caronia-Brown G, Yoshida M, Gulden F, Assimacopoulos S, Grove EA. The cortical hem regulates the size and patterning of neocortex. Development 2014, 141:2855-2865.

80. Saulnier A, Keruzore M, De Clercq S, Bar I, Moers V, Magnani D, Walcher T, Filippis C, Kricha S, Parlier D, et al. The doublesex homolog Dmrt5 is required for the development of the caudomedial cerebral cortex in mammals. Cereb Cortex 2013, 23:2552-2567.

81. Pattabiraman K, Golonzhka O, Lindtner S, Nord AS, Taher L, Hoch R, Silberberg SN, Zhang D, Chen B, Zeng $\mathrm{H}$, et al. Transcriptional Regulation of Enhancers Active in Protodomains of the Developing Cerebral Cortex. Neuron 2014.

82. O'Leary DD, Nakagawa Y. Patterning centers, regulatory genes and extrinsic mechanisms controlling arealization of the neocortex. Curr Opin Neurobiol 2002, 12:14-25. 
83. Inoue T, Tanaka T, Suzuki SC, Takeichi M. Cadherin- 6 in the developing mouse brain: expression along restricted connection systems and synaptic localization suggest a potential role in neuronal circuitry. Dev Dyn 1998, 211:338-351.

84. Korematsu K, Redies C. Expression of cadherin-8 mRNA in the developing mouse central nervous system. J Comp Neurol 1997, 387:291-306.

85. Sestan N, Rakic P, Donoghue MJ. Independent parcellation of the embryonic visual cortex and thalamus revealed by combinatorial Eph/ephrin gene expression. Curr Biol 2001, 11:39-43.

86. Miller K, Kolk SM, Donoghue MJ. EphA7-ephrin-A5 signaling in mouse somatosensory cortex: developmental restriction of molecular domains and postnatal maintenance of functional compartments. J Comp Neurol 2006, 496:627-642.

87. O'Leary DD, Wilkinson DG. Eph receptors and ephrins in neural development. Curr Opin Neurobiol 1999, 9:65-73.

88. Terakawa YW, Inoue YU, Asami J, Hoshino M, Inoue T. A sharp cadherin-6 gene expression boundary in the developing mouse cortical plate demarcates the future functional areal border. Cereb Cortex 2013, 23:2293-2308.

89. Xie Q, Yang Y, Huang J, Ninkovic J, Walcher T, Wolf L, Vitenzon A, Zheng D, Gotz M, Beebe DC, et al. Pax6 interactions with chromatin and identification of its novel direct target genes in lens and forebrain. PLoS One 2013, 8:e54507.

90. Molyneaux BJ, Arlotta P, Menezes JR, Macklis JD. Neuronal subtype specification in the cerebral cortex. Nat Rev Neurosci 2007, 8:427-437.

91. Greig LC, Woodworth MB, Galazo MJ, Padmanabhan H, Macklis JD. Molecular logic of neocortical projection neuron specification, development and diversity. Nat Rev Neurosci 2013, 14:755-769.

92. Chen B, Schaevitz LR, McConnell SK. Fezl regulates the differentiation and axon targeting of layer 5 subcortical projection neurons in cerebral cortex. Proc Natl Acad Sci U S A 2005, 102:17184-17189.

93. Molyneaux BJ, Arlotta P, Hirata T, Hibi M, Macklis JD. Fezl is required for the birth and specification of corticospinal motor neurons. Neuron 2005, 47:817-831.

94. Hevner RF, Shi L, Justice N, Hsueh Y, Sheng M, Smiga S, Bulfone A, Goffinet AM, Campagnoni AT, Rubenstein JL. Tbr1 regulates differentiation of the preplate and layer 6. Neuron 2001, 29:353-366.

95. Kwan KY, Lam MM, Krsnik Z, Kawasawa YI, Lefebvre V, Sestan N. SOX5 postmitotically regulates migration, postmigratory differentiation, and projections of subplate and deep-layer neocortical neurons. Proc Natl Acad Sci U S A 2008, 105:16021-16026.

96. Cubelos B, Sebastian-Serrano A, Beccari L, Calcagnotto ME, Cisneros E, Kim S, Dopazo A, Alvarez-Dolado M, Redondo JM, Bovolenta $\mathrm{P}$, et al. Cux1 and Cux2 regulate dendritic branching, spine morphology, and synapses of the upper layer neurons of the cortex. Neuron 2010, 66:523-535.

97. Britanova O, de Juan Romero C, Cheung A, Kwan KY, Schwark M, Gyorgy A, Vogel T, Akopov S, Mitkovski M, Agoston D, et al. Satb2 is a postmitotic determinant for upperlayer neuron specification in the neocortex. Neuron 2008, 57:378-392.

98. Sugitani Y, Nakai S, Minowa O, Nishi M, Jishage K, Kawano H, Mori K, Ogawa M, Noda T. Brn-1 and Brn-2 share crucial roles in the production and positioning of mouse neocortical neurons. Genes Dev 2002, 16:1760-1765.

99. McEvilly RJ, de Diaz MO, Schonemann MD, Hooshmand F, Rosenfeld MG. Transcriptional regulation of cortical neuron migration by POU domain factors. Science 2002, 295:1528-1532. 
100. Nieto M, Monuki ES, Tang H, Imitola J, Haubst N, Khoury SJ, Cunningham J, Gotz M, Walsh CA. Expression of Cux-1 and Cux-2 in the subventricular zone and upper layers II-IV of the cerebral cortex. J Comp Neurol 2004, 479:168-180.

101. Walsh C, Cepko CL. Clonally related cortical cells show several migration patterns. Science 1988, 241:1342-1345.

102. Luskin MB, Pearlman AL, Sanes JR. Cell lineage in the cerebral cortex of the mouse studied in vivo and in vitro with a recombinant retrovirus. Neuron 1988, 1:635-647.

103. Angevine JB, Jr., Sidman RL. Autoradiographic study of cell migration during histogenesis of cerebral cortex in the mouse. Nature 1961, 192:766-768.

104. Caviness VS, Jr., Takahashi T. Proliferative events in the cerebral ventricular zone. Brain Dev 1995, 17:159-163.

105. Rakic P. Neurons in rhesus monkey visual cortex: systematic relation between time of origin and eventual disposition. Science 1974, 183:425-427.

106. Franco SJ, Muller U. Shaping our minds: stem and progenitor cell diversity in the mammalian neocortex. Neuron 2013, 77:19-34.

107. Gotz M, Huttner WB. The cell biology of neurogenesis. Nat Rev Mol Cell Biol 2005, 6:777-788.

108. Marin O, Muller U. Lineage origins of GABAergic versus glutamatergic neurons in the neocortex. Curr Opin Neurobiol 2014, 26C:132-141.

109. Malatesta P, Hack MA, Hartfuss E, Kettenmann H, Klinkert W, Kirchhoff F, Gotz M. Neuronal or glial progeny: regional differences in radial glia fate. Neuron 2003, 37:751764.

110. Anthony TE, Klein C, Fishell G, Heintz N. Radial glia serve as neuronal progenitors in all regions of the central nervous system. Neuron 2004, 41:881-890.

111. Sessa A, Mao CA, Hadjantonakis AK, Klein WH, Broccoli V. Tbr2 directs conversion of radial glia into basal precursors and guides neuronal amplification by indirect neurogenesis in the developing neocortex. Neuron 2008, 60:56-69.

112. Kowalczyk T, Pontious A, Englund C, Daza RA, Bedogni F, Hodge R, Attardo A, Bell C, Huttner WB, Hevner RF. Intermediate neuronal progenitors (basal progenitors) produce pyramidal-projection neurons for all layers of cerebral cortex. Cereb Cortex 2009, 19:2439-2450.

113. Fietz SA, Huttner WB. Cortical progenitor expansion, self-renewal and neurogenesis-a polarized perspective. Curr Opin Neurobiol 2011, 21:23-35.

114. Gal JS, Morozov YM, Ayoub AE, Chatterjee M, Rakic P, Haydar TF. Molecular and morphological heterogeneity of neural precursors in the mouse neocortical proliferative zones. J Neurosci 2006, 26:1045-1056.

115. Stancik EK, Navarro-Quiroga I, Sellke R, Haydar TF. Heterogeneity in ventricular zone neural precursors contributes to neuronal fate diversity in the postnatal neocortex. $J$ Neurosci 2010, 30:7028-7036.

116. Hansen DV, Lui JH, Parker PR, Kriegstein AR. Neurogenic radial glia in the outer subventricular zone of human neocortex. Nature 2010, 464:554-561.

117. Wang X, Tsai JW, LaMonica B, Kriegstein AR. A new subtype of progenitor cell in the mouse embryonic neocortex. Nat Neurosci 2011, 14:555-561.

118. Shitamukai A, Konno D, Matsuzaki F. Oblique radial glial divisions in the developing mouse neocortex induce self-renewing progenitors outside the germinal zone that resemble primate outer subventricular zone progenitors. J Neurosci 2011, 31:36833695.

119. Frantz GD, Weimann JM, Levin ME, McConnell SK. Otx1 and Otx2 define layers and regions in developing cerebral cortex and cerebellum. J Neurosci 1994, 14:5725-5740. 
120. Weimann JM, Zhang YA, Levin ME, Devine WP, Brulet P, McConnell SK. Cortical neurons require Otx1 for the refinement of exuberant axonal projections to subcortical targets. Neuron 1999, 24:819-831.

121. Bulchand S, Grove EA, Porter FD, Tole S. LIM-homeodomain gene Lhx2 regulates the formation of the cortical hem. Mech Dev 2001, 100:165-175.

122. Guo C, Eckler MJ, McKenna WL, McKinsey GL, Rubenstein JL, Chen B. Fezf2 expression identifies a multipotent progenitor for neocortical projection neurons, astrocytes, and oligodendrocytes. Neuron 2013, 80:1167-1174.

123. Gao P, Postiglione MP, Krieger TG, Hernandez L, Wang C, Han Z, Streicher C, Papusheva $\mathrm{E}$, Insolera R, Chugh K, et al. Deterministic progenitor behavior and unitary production of neurons in the neocortex. Cell 2014, 159:775-788.

124. Yu YC, Bultje RS, Wang X, Shi SH. Specific synapses develop preferentially among sister excitatory neurons in the neocortex. Nature 2009, 458:501-504.

125. Kornack DR, Rakic P. Radial and horizontal deployment of clonally related cells in the primate neocortex: relationship to distinct mitotic lineages. Neuron 1995, 15:311-321.

126. Franco SJ, Gil-Sanz C, Martinez-Garay I, Espinosa A, Harkins-Perry SR, Ramos C, Muller U. Fate-restricted neural progenitors in the mammalian cerebral cortex. Science 2012, 337:746-749.

127. Cubelos B, Sebastian-Serrano A, Kim S, Moreno-Ortiz C, Redondo JM, Walsh CA, Nieto M. Cux-2 controls the proliferation of neuronal intermediate precursors of the cortical subventricular zone. Cereb Cortex 2008, 18:1758-1770.

128. Kohwi M, Doe CQ. Temporal fate specification and neural progenitor competence during development. Nat Rev Neurosci 2013, 14:823-838.

129. Seuntjens E, Nityanandam A, Miquelajauregui A, Debruyn J, Stryjewska A, Goebbels S, Nave KA, Huylebroeck D, Tarabykin V. Sip1 regulates sequential fate decisions by feedback signaling from postmitotic neurons to progenitors. Nat Neurosci 2009, 12:1373-1380.

130. Hasegawa H, Ashigaki S, Takamatsu M, Suzuki-Migishima R, Ohbayashi N, Itoh N, Takada S, Tanabe Y. Laminar patterning in the developing neocortex by temporally coordinated fibroblast growth factor signaling. J Neurosci 2004, 24:8711-8719.

131. Mizutani K, Yoon K, Dang L, Tokunaga A, Gaiano N. Differential Notch signalling distinguishes neural stem cells from intermediate progenitors. Nature 2007, 449:351355.

132. Yoon KJ, Koo BK, Im SK, Jeong HW, Ghim J, Kwon MC, Moon JS, Miyata T, Kong YY. Mind bomb 1-expressing intermediate progenitors generate notch signaling to maintain radial glial cells. Neuron 2008, 58:519-531.

133. Dong Z, Yang N, Yeo SY, Chitnis A, Guo S. Intralineage directional Notch signaling regulates self-renewal and differentiation of asymmetrically dividing radial glia. Neuron 2012, 74:65-78.

134. Alexandre P, Reugels AM, Barker D, Blanc E, Clarke JD. Neurons derive from the more apical daughter in asymmetric divisions in the zebrafish neural tube. Nat Neurosci 2010, 13:673-679.

135. Bultje RS, Castaneda-Castellanos DR, Jan LY, Jan YN, Kriegstein AR, Shi SH. Mammalian Par3 regulates progenitor cell asymmetric division via notch signaling in the developing neocortex. Neuron 2009, 63:189-202.

136. Lehtinen MK, Zappaterra MW, Chen X, Yang YJ, Hill AD, Lun M, Maynard T, Gonzalez D, Kim S, Ye P, et al. The cerebrospinal fluid provides a proliferative niche for neural progenitor cells. Neuron 2011, 69:893-905.

137. Graybiel AM. The basal ganglia. Curr Biol 2000, 10:R509-511. 
138. Kreitzer AC. Physiology and pharmacology of striatal neurons. Annu Rev Neurosci 2009, 32:127-147.

139. Anderson SA, Eisenstat DD, Shi L, Rubenstein JL. Interneuron migration from basal forebrain to neocortex: dependence on Dlx genes. Science 1997, 278:474-476.

140. Lavdas AA, Grigoriou M, Pachnis V, Parnavelas JG. The medial ganglionic eminence gives rise to a population of early neurons in the developing cerebral cortex. J Neurosci 1999, 19:7881-7888.

141. Wichterle H, Garcia-Verdugo JM, Herrera DG, Alvarez-Buylla A. Young neurons from medial ganglionic eminence disperse in adult and embryonic brain. Nat Neurosci 1999, 2:461-466.

142. Butt SJ, Fuccillo M, Nery S, Noctor S, Kriegstein A, Corbin JG, Fishell G. The temporal and spatial origins of cortical interneurons predict their physiological subtype. Neuron 2005, 48:591-604.

143. Wichterle H, Turnbull DH, Nery S, Fishell G, Alvarez-Buylla A. In utero fate mapping reveals distinct migratory pathways and fates of neurons born in the mammalian basal forebrain. Development 2001, 128:3759-3771.

144. Sussel L, Marin O, Kimura S, Rubenstein JL. Loss of Nkx2.1 homeobox gene function results in a ventral to dorsal molecular respecification within the basal telencephalon: evidence for a transformation of the pallidum into the striatum. Development 1999, 126:3359-3370.

145. Butt SJ, Sousa VH, Fuccillo MV, Hjerling-Leffler J, Miyoshi G, Kimura S, Fishell G. The requirement of Nkx2-1 in the temporal specification of cortical interneuron subtypes. Neuron 2008, 59:722-732.

146. Flames N, Pla R, Gelman DM, Rubenstein JL, Puelles L, Marin O. Delineation of multiple subpallial progenitor domains by the combinatorial expression of transcriptional codes. J Neurosci 2007, 27:9682-9695.

147. Wonders CP, Taylor L, Welagen J, Mbata IC, Xiang JZ, Anderson SA. A spatial bias for the origins of interneuron subgroups within the medial ganglionic eminence. Dev Biol 2008, 314:127-136.

148. Fogarty M, Grist M, Gelman D, Marin O, Pachnis V, Kessaris N. Spatial genetic patterning of the embryonic neuroepithelium generates GABAergic interneuron diversity in the adult cortex. J Neurosci 2007, 27:10935-10946.

149. Sousa VH, Miyoshi G, Hjerling-Leffler J, Karayannis T, Fishell G. Characterization of Nkx6-2-derived neocortical interneuron lineages. Cereb Cortex 2009, 19 Suppl 1:i1-10.

150. Batista-Brito R, Fishell G. The developmental integration of cortical interneurons into a functional network. Curr Top Dev Biol 2009, 87:81-118.

151. Wonders CP, Anderson SA. The origin and specification of cortical interneurons. Nat Rev Neurosci 2006, 7:687-696.

152. Pilz GA, Shitamukai A, Reillo I, Pacary E, Schwausch J, Stahl R, Ninkovic J, Snippert HJ, Clevers H, Godinho L, et al. Amplification of progenitors in the mammalian telencephalon includes a new radial glial cell type. Nat Commun 2013, 4:2125.

153. Miyoshi G, Butt SJ, Takebayashi H, Fishell G. Physiologically distinct temporal cohorts of cortical interneurons arise from telencephalic Olig2-expressing precursors. $J$ Neurosci 2007, 27:7786-7798.

154. Miller MW. Cogeneration of retrogradely labeled corticocortical projection and GABAimmunoreactive local circuit neurons in cerebral cortex. Brain Res 1985, 355:187-192.

155. Fairen A, Cobas A, Fonseca M. Times of generation of glutamic acid decarboxylase immunoreactive neurons in mouse somatosensory cortex. J Comp Neurol 1986, 251:6783. 
156. Valcanis H, Tan SS. Layer specification of transplanted interneurons in developing mouse neocortex. J Neurosci 2003, 23:5113-5122.

157. Brown KN, Chen S, Han Z, Lu CH, Tan X, Zhang XJ, Ding L, Lopez-Cruz A, Saur D, Anderson SA, et al. Clonal production and organization of inhibitory interneurons in the neocortex. Science 2011, 334:480-486.

158. Ciceri G, Dehorter N, Sols I, Huang ZJ, Maravall M, Marin O. Lineage-specific laminar organization of cortical GABAergic interneurons. Nat Neurosci 2013, 16:1199-1210.

159. Liodis P, Denaxa M, Grigoriou M, Akufo-Addo C, Yanagawa Y, Pachnis V. Lhx6 activity is required for the normal migration and specification of cortical interneuron subtypes. $J$ Neurosci 2007, 27:3078-3089.

160. Du T, Xu Q, Ocbina PJ, Anderson SA. NKX2.1 specifies cortical interneuron fate by activating Lhx6. Development 2008, 135:1559-1567.

161. Zhao Y, Flandin P, Long JE, Cuesta MD, Westphal H, Rubenstein JL. Distinct molecular pathways for development of telencephalic interneuron subtypes revealed through analysis of Lhx6 mutants. J Comp Neurol 2008, 510:79-99.

162. Fragkouli A, van Wijk NV, Lopes R, Kessaris N, Pachnis V. LIM homeodomain transcription factor-dependent specification of bipotential MGE progenitors into cholinergic and GABAergic striatal interneurons. Development 2009, 136:3841-3851.

163. Cho HH, Cargnin F, Kim Y, Lee B, Kwon RJ, Nam H, Shen R, Barnes AP, Lee JW, Lee S, et al. Isl1 directly controls a cholinergic neuronal identity in the developing forebrain and spinal cord by forming cell type-specific complexes. PLoS Genet 2014, 10:e1004280.

164. Lopes R, Verhey van Wijk N, Neves G, Pachnis V. Transcription factor LIM homeobox 7 (Lhx7) maintains subtype identity of cholinergic interneurons in the mammalian striatum. Proc Natl Acad Sci U S A 2012, 109:3119-3124.

165. Waclaw RR, Wang B, Pei Z, Ehrman LA, Campbell K. Distinct temporal requirements for the homeobox gene Gsx2 in specifying striatal and olfactory bulb neuronal fates. Neuron 2009, 63:451-465.

166. Stenman J, Toresson H, Campbell K. Identification of two distinct progenitor populations in the lateral ganglionic eminence: implications for striatal and olfactory bulb neurogenesis. J Neurosci 2003, 23:167-174.

167. Toresson H, Campbell K. A role for Gsh1 in the developing striatum and olfactory bulb of Gsh2 mutant mice. Development 2001, 128:4769-4780.

168. Pei Z, Wang B, Chen G, Nagao M, Nakafuku M, Campbell K. Homeobox genes Gsx1 and Gsx2 differentially regulate telencephalic progenitor maturation. Proc Natl Acad Sci U S A 2011, 108:1675-1680.

169. Miyoshi G, Hjerling-Leffler J, Karayannis T, Sousa VH, Butt SJ, Battiste J, Johnson JE, Machold RP, Fishell G. Genetic fate mapping reveals that the caudal ganglionic eminence produces a large and diverse population of superficial cortical interneurons. J Neurosci 2010, 30:1582-1594.

170. Kanatani S, Yozu M, Tabata H, Nakajima K. COUP-TFII is preferentially expressed in the caudal ganglionic eminence and is involved in the caudal migratory stream. J Neurosci 2008, 28:13582-13591.

171. Macdonald R, Barth KA, Xu Q, Holder N, Mikkola I, Wilson SW. Midline signalling is required for Pax gene regulation and patterning of the eyes. Development 1995, 121:3267-3278.

172. Corbin JG, Rutlin M, Gaiano N, Fishell G. Combinatorial function of the homeodomain proteins Nkx2.1 and Gsh2 in ventral telencephalic patterning. Development 2003, 130:4895-4906. 
173. Zhao Y, Flandin P, Vogt D, Blood A, Hermesz E, Westphal H, Rubenstein JL. Ldb1 is essential for development of $\mathrm{Nkx} 2.1$ lineage derived GABAergic and cholinergic neurons in the telencephalon. Dev Biol 2014, 385:94-106.

174. Vierbuchen T, Ostermeier A, Pang ZP, Kokubu Y, Sudhof TC, Wernig M. Direct conversion of fibroblasts to functional neurons by defined factors. Nature 2010, 463:1035-1041.

175. Vierbuchen T, Wernig M. Molecular roadblocks for cellular reprogramming. Mol Cell 2012, 47:827-838.

176. Shen Q, Wang Y, Dimos JT, Fasano CA, Phoenix TN, Lemischka IR, Ivanova NB, Stifani S, Morrisey EE, Temple S. The timing of cortical neurogenesis is encoded within lineages of individual progenitor cells. Nat Neurosci 2006, 9:743-751.

Figure 1

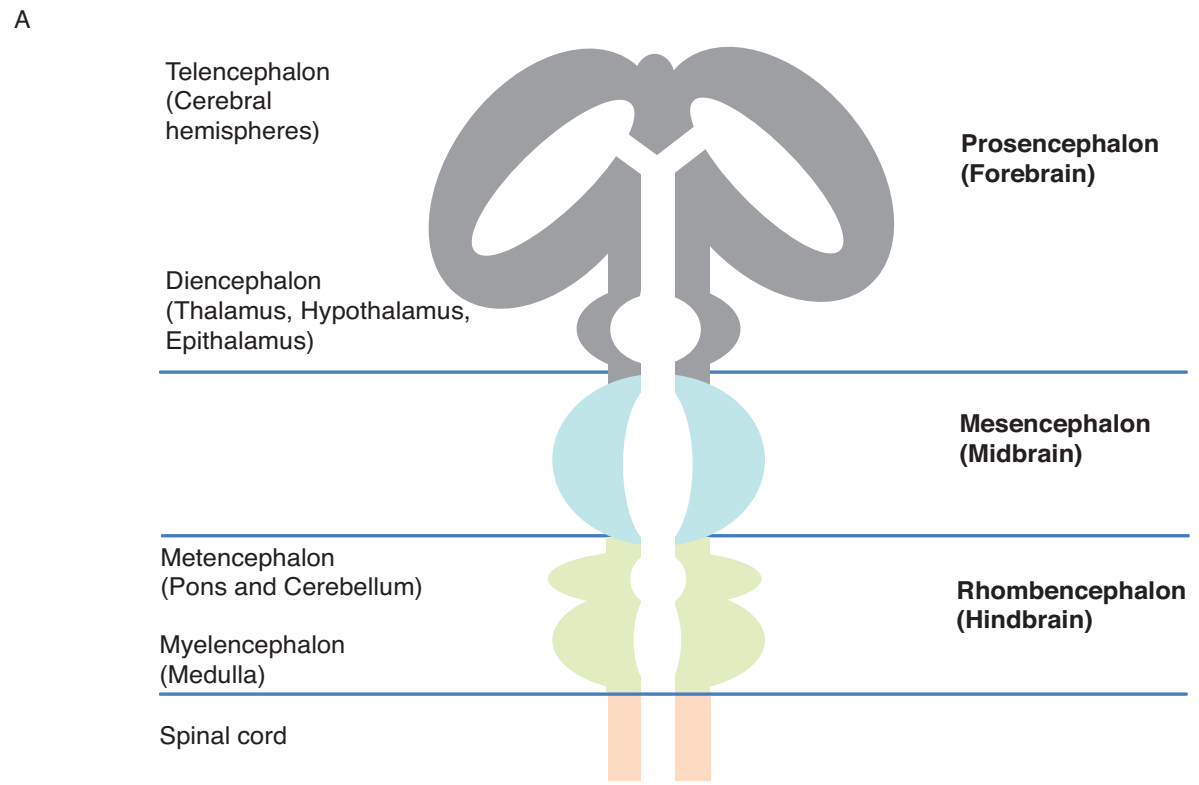

B

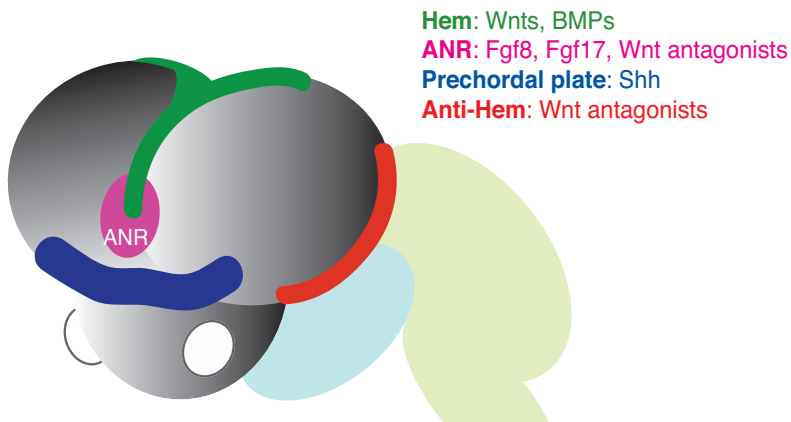

C

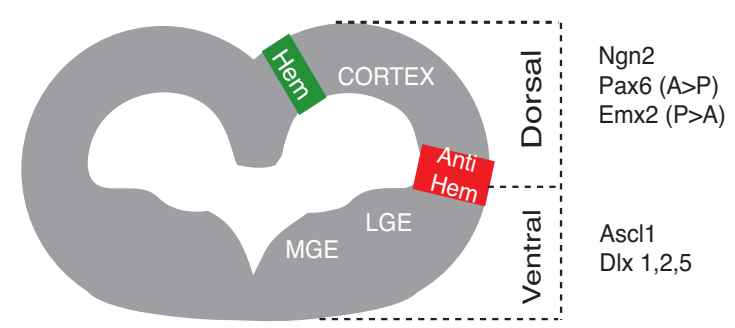


Figure 2

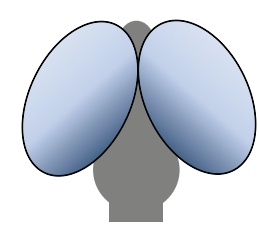

$\mathrm{P}>\mathrm{A}$

$M>L$

Emx2 +/-

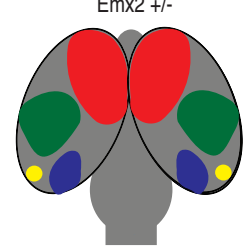

Caudo-medial expansion of frontal areas
Pax6

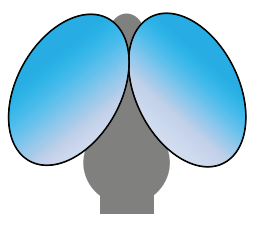

A $>$ P

$L>M$

Pax6 sey/sey

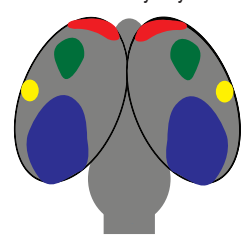

Contraction of rostral areas and expansion of caudal

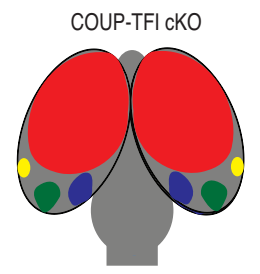

Expansion of rostral areas

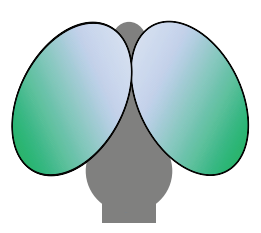

$P>A$
$L>M$
SP8
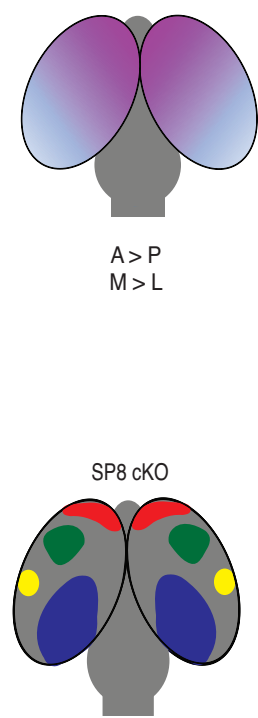

Contraction of rostral areas and expansion of caudal areas

\section{Figure 3}

A

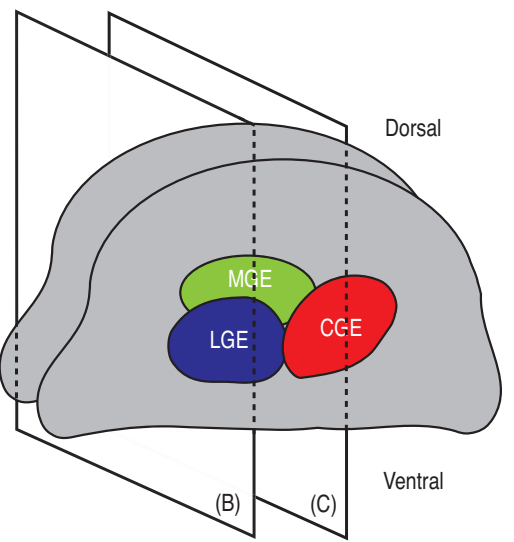

B

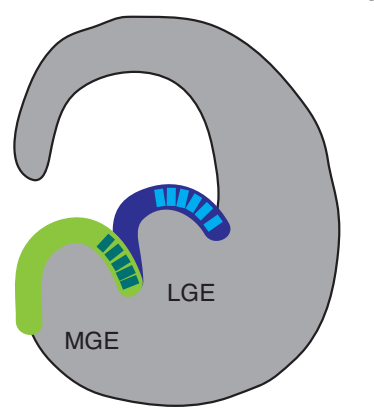

C

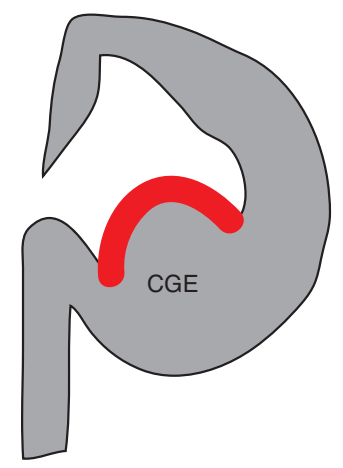

1. dLGE Gsx2+, Er81+ : olfactory GABA interneurons

vLGE Gsx2+, Isl1+ : striatal GABA interneurons LGE Gsx2+ : striatal MSN

d dMGE Nkx2.1+, Nkx6.2+ : cortical GABA interneurons (CR+, SST+ Martinotti cells) VMGE Nkx2.1 > Lhx6 : Lhx6ON, Nkx2.1OFF : cortical GABA interneurons

VMGE Nkx2.1 > Lhx6 : Lhx6ON, Nkx2.1ON : striatal GABA interneurons

VMGE Nkx2.1 > Lhx6 : Lhx6OFF, Lhx7ON, Isl1ON : striatal ChAT interneurons

CGE: COUP-TFII: $30 \%$ of cortical GABA interneurons (VIP+, 5HT3a+, Reelin+, SP8+) 